\title{
Socioeconomic inequalities in height, leg length and trunk length among children aged 6.5 years and their parents from the Republic of Belarus: Evidence from the Promotion of Breastfeeding Intervention Trial (PROBIT)
}

\author{
Rita Patel ${ }^{1}$, Debbie A. Lawlor ${ }^{1,2}$, Michael S. Kramer ${ }^{3}$, George Davey Smith ${ }^{1,2}$, Natalia \\ Bogdanovich $^{4}$, Lidia Matush ${ }^{4}$, and Richard M. Martin ${ }^{1,2}$ \\ ${ }^{1}$ School of Social and Community Medicine, University of Bristol, Bristol, UK \\ ${ }^{2} \mathrm{MRC}$ Centre for Causal Analyses in Translational Epidemiology (CAiTE), University of Bristol, \\ Bristol, UK \\ ${ }^{3}$ Department of Pediatrics and Department of Epidemiology, Biostatistics and Occupational \\ Health, McGill University Faculty of Medicine, Montreal, Canada \\ ${ }^{4}$ The National Research and Applied Medicine Mother and Child Centre, Minsk, Belarus
}

\section{Abstract}

\begin{abstract}
Background-Lower socioeconomic position is associated with shorter stature, in particular shorter leg length, but the magnitude of these associations in non-Western countries has received little attention.
\end{abstract}

\begin{abstract}
Aim-To examine socioeconomic differentials in height, leg and trunk length in 6.5 year olds from the Republic of Belarus and compare these to differentials in parental height.

Methods-Multivariable linear regression was used to examine associations in a cohort of 13 889 children.

Results-Children from non-manual households were $1.0 \mathrm{~cm}$ (95\% confidence interval: $0.7-1.3$ $\mathrm{cm})$ taller than those from manual households. Mothers and fathers from non-manual backgrounds were $0.7 \mathrm{~cm}(0.5-0.8)$ and $1.8 \mathrm{~cm}(1.6-2.0)$ taller than those from manual backgrounds, respectively. Associations with higher parental educational attainment were similar. The magnitudes of the associations of socioeconomic position with leg length were similar to those with trunk length. Adjusting for mid-parental height and number of older siblings attenuated associations markedly.
\end{abstract}

Conclusions-In Belarus, similar socioeconomic differentials in height were observed in both children and their parents. Among children, height differentials were partly explained by midparental height and number of older siblings. Leg length was not a more sensitive indicator of childhood socioeconomic conditions than trunk length.

\section{Keywords}

Height; leg length; trunk length; socioeconomic factors

Copyright $(\odot$ Informa UK, Ltd.

Correspondence: Rita Patel, School of Social and Community Medicine, University of Bristol, Canynge Hall, 39 Whatley Road, Bristol BS8 2PS, UK. rita.patel@ bristol.ac.uk.

The authors report no conflicts of interest. The authors alone are responsible for the content and writing of the paper. 


\section{INTRODUCTION}

Socioeconomic variation in adult height has been reported in many developed and developing countries (Meyer and Selmer 1999; Cavelaars et al. 2000; Hakeem 2001), although few studies (Webb et al. 2008) have been set in former Soviet countries. In all settings, consistent positive associations have been observed between height and more affluent socioeconomic circumstances (as measured for example by education (Meyer and Selmer 1999; Cavelaars et al. 2000; Webb et al. 2008), occupation (Silventoinen et al. 2001) and family income (Meyer and Selmer 1999; Hakeem 2001)). In one study of adults from 10 European countries, more educated men were $1.6-3.0 \mathrm{~cm}$ taller than less educated men and among women this difference was 1.2-2.2 cm (Cavelaars et al. 2000). These length/height inequalities were apparent from birth (Howe et al. 2010). Height in childhood is a good predictor of height in adulthood and, although shortfalls in height developed during childhood are reduced by adulthood, differences remain after puberty (Li et al. 2004b). Some studies suggest that childhood height inequalities may have diminished in developed countries, mainly due to greater height gain within manual social groups (Mackenbach 1991; $\mathrm{Li}$ et al. 2004a). For example, differences in height among British children aged 7 years, comparing those from semi/unskilled manual families to those from professional/managerial families, reduced from $\sim 2 \mathrm{~cm}$ shorter to less than $1 \mathrm{~cm}$ shorter over two generations (Li et al. 2004a). However, in some developed countries, disparities in childhood height are still marked (Batty and Leon 2002; Freitas et al. 2007).

The importance of these findings is that attained adult height, which reflects birth length and childhood growth and hence intra-uterine and childhood circumstances, are related to a number of important health outcomes in adulthood. These include a negative association with coronary heart disease (Wannamethee et al. 1998) and a positive association with some cancers (Gunnell et al. 2001). Little is known about the mechanisms that explain socioeconomic differentials in height, particularly during childhood, a period in the lifecourse that is sensitive to growth influencing exposures.

Most previous studies have been set in Western populations and factors explaining socioeconomic differentials in height have not been extensively explored among children in former Soviet countries. Contemporary adults in these countries spent the majority of their childhoods under a communist regime, in which occupational wage differences were less marked compared to Western countries and education did not necessarily lead to higher income (Bobak et al. 2000). Given these social conditions one might expect little socioeconomic height variation among adults who were born in the communist era. After the fall of communism in 1989 and the subsequent economic changes, it is postulated that education may have become more important in relation to income (Bobak et al. 2000) and inequalities may have increased. Given these conditions one might expect there to be greater socioeconomic height inequalities among contemporary children than among their parents. Changes in income inequalities in Belarus over time are demonstrated by the average wage ratio of the financing, insurance, real estate and business services sector to the agriculture, hunting, forestry and fishing sector, which was 1.02 in 1988 and increased to 2.82 by 1996 (International Labour Office Department of Statistics 2011).

Pre-natal factors associated with shorter childhood height include late birth order ( $\mathrm{Li}$ and Power 2004; Lawson and Mace 2008), maternal alcohol intake (Day et al. 2002) and maternal smoking during pregnancy (Leary et al. 2006). Post-natal factors associated with being short in childhood include having been formula rather than breastfed (Martin et al. 2002), low consumption of cow's milk (even when overall nutrition is adequate) (Hoppe et al. 2006), poor general nutritional intake (Silventoinen 2003), greater number of siblings ( $\mathrm{Li}$ 
and Power 2004; Whitley et al. 2008), shorter parental height (Sichieri et al. 2000; Li et al. 2004b), psychosocial stresses such as parental divorce ( $\mathrm{Li}$ et al. 2004b), exposure to passive smoke (Rona et al. 1985) and infant/childhood illnesses (Martin et al. 2010). Many of these factors are also associated with deprived socioeconomic circumstances (Lynch et al. 1997; Vingraite et al. 2004; Cohen et al. 2010). Hence, these characteristics could all potentially be mediators of the association between parental socioeconomic position and child height.

Previous studies suggest socioeconomic variation in height is driven mainly by variation in leg length as opposed to trunk length (Gunnell et al. 1998; Batty and Leon 2002; Li et al. 2007) and that leg length may be a more sensitive indicator of early socioeconomic and associated environmental factors than trunk length (Gunnell et al. 1998; Whitley et al. 2008), particularly for those factors present during the pre-pubertal period (Gunnell 2001).

This study is set in the Republic of Belarus which was part of the Union of Soviet Socialist Republics for nearly 70 years until 1991, when Belarus attained independence and subsequently joined the Commonwealth of Independent States. Belarus is a middle-income country which has undergone economic change since 1989 and has features in common with many high-income countries: high adult literacy and low child mortality rates, but it also has high rates of adult mortality, principally from ischemic heart disease (World Health Organisation 2009). Life expectancy at birth in Belarus in 2007 was 65 years for men and 76 years for women (World Bank 2010).

In our large prospective cohort study ( $n=13889)$, we aim to: (i) determine the magnitude of socioeconomic differentials in childhood height, leg length and trunk length in a contemporary population of Belarusian children aged 6.5 years who were born between 1996-1997 and were thus in utero and spent all of their lives in the post-communist era; (ii) examine if variation in leg rather than trunk length better explain socioeconomic differentials among children; (iii) compare socioeconomic differentials in height in these children to those of their parents who were born and spent their childhood in the communist era; and (iv) explore the extent to which childhood socioeconomic disparities in height, leg and trunk length are explained by factors that are known to be related to childhood skeletal growth.

\section{METHODS \\ The PROBIT study}

The study cohort comprises infants and their parents who were originally recruited into the Promotion of Breastfeeding Intervention Trial (PROBIT) (Kramer et al. 2000) and attended a follow-up interview and examination when the children were aged 6.5 years. The original trial was a multicentre, cluster-randomized controlled trial in the Republic of Belarus, in which the experimental intervention was the promotion of exclusive and prolonged breastfeeding modelled on the Baby-Friendly Hospital Initiative (WHO/UNICEF 1989). A detailed description of the original trial has been published previously (Kramer et al. 2000). Briefly, 31 maternity hospitals and one of their affiliated polyclinics (outpatient clinics where children are followed-up for routine health care) were randomly assigned to receive the breastfeeding promotion intervention or to continue with prevailing practices. Between June 1996-December 1997, 17046 mother-infant pairs were recruited during their postpartum hospital stay. Inclusion criteria specified that infants were initially breastfed and were born full-term ( $\geq 37$ weeks gestation), healthy and singleton, weighed at least $2500 \mathrm{~g}$ and had an Apgar score $\geq 5$ at 5 minutes; mothers were also healthy without contraindications to breastfeeding. These children were followed-up at polyclinic visits at 1 , 2, 3, 6, 9 and 12 months. Since all mothers initially breastfed, the experimental intervention was designed to increase the duration and exclusivity of breastfeeding (Kramer et al. 2001). 
When the children were aged 6.5 years they were invited to a follow-up interview and examination between December 2002-April 2005; 13889 (81.5\%) children were examined at 31 polyclinics by one of 38 trained study paediatricians (Kramer et al. 2007). Mean age at examination was 6.6 years (standard deviation, SD, 0.3, interquartile range 6.5-6.7 years). Monitoring visits were conducted during recruitment and follow-up to ensure compliance with study protocols.

\section{Child anthropometric measures and parental height}

At the follow-up examination at age 6.5 years, standing and sitting height were measured in duplicate and the mean values used in all analyses (Kramer et al. 2007). Standing height was measured with a stadiometre with a movable headboard (Medtechnika, Pinsk, Belarus). The child stood without shoes and with the heels of both feet together touching the base of the wall. The head was aligned in the Frankfurt horizontal plane. Once correctly positioned, the headboard was lowered and the child instructed to take a deep breath and stand as tall as possible. The headboard was positioned firmly on top of the head with sufficient pressure to compress the hair. The measurement was read in centimetres and recorded to the nearest millimetre. Sitting height was measured with the same stadiometre and the addition of a uniform, standard wooden bench of known height. The child sat on the stool, with the head positioned in the Frankfurt plane. The child was instructed to take in a deep breath and sit up as tall as possible and the measurement taken in the same way as standing height. In total, 13 872 children had both measures of height at follow-up. Sitting height minus the height of the standard bench gives a measure of trunk length and leg length was derived from standing height minus trunk length.

At the same 6.5 year visit, the examining paediatrician recorded parental height (and other covariables) during an interview with the accompanying parent/legal guardian. For most (91\%) of the children, the mother reported height for both herself and the child's father; in a minority (8\%) the father/guardian reported for both parents (for $1 \%$ of children, this information was not recorded). In total, of the 13889 children that returned for a follow-up examination, $1352(10 \%)$ of the fathers and $155(1 \%)$ of the mothers did not have a reported height. Mid-parental height was calculated as the mean of the two parents' heights.

\section{Socioeconomic position}

The mother reported both parents' occupations and educational attainment levels when the child was enrolled into the study during the post-partum hospital stay. Occupation was classified as a binary variable: manual worker/farmer (considered as a manual socioeconomic classification); service worker (non-manual socioeconomic classification). Those who reported they were pupils, students, housewives, unemployed or whose occupation was unknown were coded as missing, because the relationship of these categories to usual socioeconomic position was unclear. The highest household occupation was calculated as the higher of the occupation categories for the mother or the father; a nonmanual worker was regarded as a higher occupational status than a manual worker (the reference category). Highest household occupation was missing for $6 \%(n=899)$ of households. Educational status was recoded from seven to three categories: initial or incomplete or common secondary; advanced secondary or partial university; and completed university. The original category 'unknown' was coded as missing. In total, no mothers and 468 (3\%) fathers had missing data for educational attainment.

\section{Other covariables}

The location of the polyclinic was categorized as either in East or West Belarus and as urban or rural. The mother reported the following baseline variables at recruitment: the ages of the 
parents at birth of the child (in completed years), number of older siblings $(0,1$ or $2+)$ and marital status. The father's age was not obtained for (4\%) children.

We included trial randomization arm as the best assessment of the mediating effect of breastfeeding on child height (Kramer et al. 2002). The proportion of women who were exclusively breastfeeding was 7 -fold higher in the promotion arm at 3 months compared to the control arm (43.3 vs 6.4\%) and >12-fold higher at 6 months ( 7.9 vs $0.6 \%$ ) (Kramer et al. 2001). We included exclusive breastfeeding at 3 months as a covariable to examine the observational association between breastfeeding and height. At each clinic visit cow's milk consumption in millilitres per day was recorded and used to derive timing of cow's milk consumption (none consumed in first 12 months, consumed in first 3 months, consumed between > 3-12 months) and the amount of cow's milk consumed in infancy (none, low and high) based on dividing cow's milk consumption into two groups by the median value. The 'low' cow's milk group consumed an average of $52 \mathrm{ml} /$ day of cow's milk and the 'high' group consumed $214 \mathrm{ml} / \mathrm{day}$. Only those with data at all six visits in infancy were included in the derivation of the cow's milk variables (95\%). At the same clinic visits reports of hospitalization of the infant for any illness were recorded, as well as hospitalizations for gastrointestinal and respiratory illnesses.

The following covariables were recorded at the 6.5 year follow-up visit: smoking for both parents, recoded to yes/no from the number of cigarettes smoked per day; data were missing for 120 mothers (1\%) and 1292 fathers (9\%). Reported maternal smoking during pregnancy was not used in this analysis, as only $2 \%$ of mothers claimed they smoked during the pregnancy. Parental alcohol intake was derived by combining the average frequency of alcohol consumption and amount of alcohol consumed (categorized as $\langle 1,1-2\rangle=$,2 units per week for mothers and $<1,1-2,3-4,>4$ units per week for fathers). One unit of alcohol is equivalent to $25 \mathrm{ml}$ of vodka or spirit (Department of Health 2007). Data regarding alcohol intake were missing for 232 mothers (2\%) and 1437 fathers (10\%). The number of younger siblings since the birth of the study child $(0,1+)$ was also recorded; data were missing for 112 children (1\%). The total number of siblings was calculated from the number of older and younger siblings $(0,1,2+)$. Marital status was recorded again and coded as: Mother's marital status at birth of child and at 6.5 year follow-up either 'married and married' or 'married and not married'. The paediatricians recorded any report of hospitalizations for gastrointestinal infection or respiratory illness (pneumonia or asthma) in the child's medical record since the age of 12 months. These reports were combined to give a variable for hospitalization for either reason in childhood. The institutional review board of the Montreal Children's Hospital approved the study and participating mothers gave signed consent in Russian.

\section{Statistical methods}

The child's exact age was calculated from the date of birth and date of follow-up examination. Children's height measures at follow-up were age-adjusted using linear regression. Height/leg/trunk measures in excess of $\pm 4 \mathrm{SD}$ from the mean were not used in the analyses and 64 children, seven mothers and four fathers were excluded because of having such extreme measurements. Only those children with complete measures for all ageadjusted height/leg/trunk measures were included in the analyses.

Correlation coefficients between all child age-standardized height measures and parental heights were calculated. The basic age-adjusted association between the socioeconomic indicators and continuous height/leg/trunk measures were estimated using linear regression. Multivariable linear regression was used to adjust for covariables. The factors considered as potential covariables are given in Supplementary Tables 1 and 2. The association of each variable with height/leg/trunk measures was examined; associations that met the a priori 
level of statistical significance $p \leq 0.1$ or difference $\geq 0.5 \mathrm{~cm}$ between extreme categories of the explanatory variable were included in the final linear regression models. For children, the basic model controlled for polyclinic location (urban/rural location and East/West Belarus) which may influence opportunities for parental education and occupation and thus may confound the socioeconomic position-height associations (model 1). In model 2, we additionally adjusted for study trial arm (intervention or control) as a means of examining the extent to which breastfeeding mediated the association of socioeconomic position with height/leg/trunk measures. Model 3 was additionally adjusted for factors measured around birth and age 6.5 years. In model 3, parental smoking, parental alcohol intake and number of siblings were considered to reflect the environment within which the child grew up and which could influence childhood height and thus mediate associations between socioeconomic position and height. Model 4 additionally adjusted for hospitalizations in infancy or childhood and model 5 additionally adjusted for mid-parental height. The study trial arm (intervention or control) not only provided the best estimate of the association of breastfeeding with height but was also included as a dummy variable in all subsequent regression models, as is conventional when randomized trials are used as cohort studies. As it is not clear when each covariable may influence the socioeconomic position and height association we pragmatically chose the order of the covariables in models 3-5, grouping similar factors (e.g. factors reflecting the child's home environment in model 3 and hospital illness in model 4). Mid-parental height captures both elements of shared environment and genes and was added separately, in model 5, to examine its effect over and above the effects of other covariables.

For the parents, the study trial arm (intervention or control) was included as a dummy variable in all regression models for the reason previously described. The basic model adjusted for age and study trial arm (model 1) was additionally adjusted for polyclinic location urban/rural location and East/West Belarus (as these may confound the associations examined) in model 2 and for own smoking and alcohol intake in model 3. Current smoking and alcohol intake may act as proxies for tobacco and alcohol consumption during adolescence, which may in turn influence attained adult height. In each multivariable analysis, only those with complete data on all covariables in any model were included. In all models, robust standard errors were used to compute confidence intervals and $p$-values to account for possible non-independence of measurements within an individual hospital/ polyclinic site (clustering). Differences in association by sex (for both children and parents) were investigated using the likelihood ratio test for interaction based on the maximally adjusted models. $F$-statistics were computed to determine statistical evidence of a difference between maternal and paternal height associations with offspring height measures. The $r^{2}$ statistic was computed to determine the proportion of child height variation explained by socioeconomic position in the basic model for each of height, leg and trunk length. All analyses were conducted using Stata version 11.0 (Stata Corporation, Texas).

\section{RESULTS}

Children's mean age-adjusted height was $120.6 \mathrm{~cm}(\mathrm{SD}=5.0)$, leg length $55.3 \mathrm{~cm}(\mathrm{SD}=$ $3.2)$ and trunk length $65.4 \mathrm{~cm}(\mathrm{SD}=2.9)$. Supplementary Table 1 shows associations of parental age (at the birth of the child) and height with the height of the children measured at age 6.5 years (mean age 6.6 years, $\mathrm{SD}=0.3$ ). Fathers were on average $11.7 \mathrm{~cm}$ taller than mothers. Parent's heights were strongly associated with offspring height measures, with a $1.8 \mathrm{~cm}$ change in child's standing height per standard deviation increase in mother's height and $1.7 \mathrm{~cm}$ per standard deviation increase in father's height. There was moderate statistical evidence that there was a difference in the association of mothers height compared to fathers height with child height $(p>0.10)$. We chose to use mid-parental height to summarize both parents' heights in subsequent analyses. 
Supplementary Table 2 shows other covariables measured during infancy and childhood. Just over half the children were first born and a quarter of children had younger siblings by the age of 6.5 years. More than half the children consumed cow's milk within the first 12 months. A quarter of children were hospitalized during their first year and over a tenth had been hospitalized between the ages of 1-6.5 years. Fathers were more likely to smoke or consume alcohol than mothers.

Supplementary Tables 1 and 2 also show the associations of parental, infant and childhood characteristics with childhood standing height, leg length and trunk length: breastfeeding (as indicated by exclusive breastfeeding at 3 months), cow's milk consumption in infancy (either by dose or timing) and change in mothers' marital status were not strongly associated with standing height/leg/trunk measures. Hospitalizations in infancy (for gastrointestinal infection, respiratory problems or any reason) and childhood (for any reason), parent's height, age at the child's birth, smoking and alcohol intake, breastfeeding (as indicated by the study trial arm) and number of older and younger siblings (and total number of siblings) were all associated with height measures.

Supplementary Table 3 shows correlation coefficients between all child age-adjusted height measurements and parent height. Mothers' and fathers' heights were weakly positively correlated with each other (Pearson's correlation coefficient 0.27). Child leg and trunk length at age 6.5 years were also weakly positively correlated with each other (coefficient $0.29)$ and both were strongly positively correlated with standing height $(0.78-0.83)$. Midparental, maternal and paternal heights were each moderately correlated with children's height measurements $(0.28-0.44)$.

Tables I-III show multivariable associations between socioeconomic indicators and the three height outcomes measured in childhood (standing height, leg and trunk length, respectively). There was little evidence of interaction between socioeconomic position and sex of the child for any of the height measures in these models (all $p \geq 0.3$ ) and therefore all associations are presented for both genders combined.

In the basic age-adjusted models, higher levels of mother's education, father's education and highest household occupation were all associated with greater height, leg and trunk length. The difference in standing height between categories of socioeconomic indicators and the reference groups (manual worker or lowest level of education) varied between $0.45-1.86$ $\mathrm{cm}$. Associations with standing height were attenuated by between $21-34 \%$ in model 3 (which controlled for East or West of Belarus and urban or rural residence, study trial arm, parent's age, smoking and alcohol intake, number of older and younger siblings) compared to model 1 (controlling for East or West of Belarus and urban or rural residence only); the number of older siblings was the main driver of the attenuation and reduced the association between socioeconomic measures and standing height by 2-13\%. Neither replacing older and younger siblings with total number of siblings in the model, nor controlling for any hospitalizations in infancy and childhood (model 4) had any important effect on the observed associations; neither did controlling for hospitalization for gastrointestinal infection or respiratory problems in infancy and childhood, instead of 'any hospitalization'. When all other potential explanatory variables (shown in Supplementary Tables 1 and 2, except parental height) were controlled for in model 4, the difference in height measures by socioeconomic factors remained the same as in model 3 . The association was attenuated by between $42-73 \%$ after controlling for mid-parental height (model 5 compared to model 4). The findings for leg and trunk length were similar to those for standing height.

The proportion of height variation explained by the three measures of socioeconomic position (based on the $r^{2}$ statistic for model 1) varied from $0.5-1.0 \%$ for leg length, 1.1- 
$1.8 \%$ for trunk length and $0.9-1.8 \%$ for standing height. Mid-parental height and number of older siblings together attenuated the associations of socioeconomic position with childhood height by 39-64\% when added to Model 1.

Table IV shows the difference in height by socioeconomic group among mothers and fathers. Examining model 2 which accounts for age, trial arm and area of residence, university educated mothers were $0.8 \mathrm{~cm}$ taller than mothers educated up to common secondary standard (reference group). Fathers who were university educated were over $2 \mathrm{~cm}$ taller than those educated up to common secondary standard. Fathers with university educated partners were almost $3 \mathrm{~cm}$ taller than fathers with the least educated partners and the difference in height among men was greater by their partner's educational level than by their own educational level after adjustment. Fathers from manual households were $1.8 \mathrm{~cm}$ shorter than fathers from non-manual households and mothers $0.7 \mathrm{~cm}$ shorter after adjustment (model 2). There was little attenuation of the effect estimates across models 1-3.

\section{DISCUSSION}

Socioeconomic differentials in height were observed among both children and their parents in the Republic of Belarus. There was a positive association between socioeconomic position (measured by level of parental educational attainment or manual vs non-manual occupation) and standing height for all family members. We found those from non-manual households were taller than those from manual households by: $1.0 \mathrm{~cm}$ for children; $0.7 \mathrm{~cm}$ for mothers and $1.8 \mathrm{~cm}$ for fathers (after controlling for age and area of residence). Among children aged 6.5 years in this population, leg length did not appear to be a more sensitive indicator of early environmental conditions than trunk length. Adjustment for mid-parental height and number of older siblings both markedly attenuated the associations between socioeconomic position and childhood standing height.

Our findings among children are similar in magnitude and gradient to those reported in many Western (Mackenbach 1991; Batty and Leon 2002) and Eastern European countries (Bobak et al. 1994). The magnitude of height inequalities between mothers and fathers is marked for both education and household occupation. Although the parents in our study grew up under a communist regime when there were little income inequalities based on average wages, socioeconomic height differentials were still apparent and similar to those seen in other studies (both in former Soviet countries (Webb et al. 2008) and Europe (Cavelaars et al. 2000)) and similar in size to those seen among their children, who are currently living in a period of higher wage inequalities after major economic changes.

Some studies have reported that height differentials arise mostly due to variation in leg length (Gunnell et al. 1998). Leg and trunk length contributed almost equally to the socioeconomic differentials in childhood height in our study. The proportion of variability accounted for by either leg length or trunk length was similar. This suggests that leg length was not a more sensitive indicator of pre-pubertal socioeconomic conditions than trunk length in this population, contrary to findings by Gunnell et al. (1998). This disparity in results may be due to differences between the era and populations studied; our cohort is contemporary and based in a middle-income country, as compared to those children born in the UK in the 1930s when socioeconomic conditions were generally poorer (Gunnell et al. 1998). Another study in the Czech Republic, Poland and Russia also found no difference in the sensitivity of leg compared to trunk length to childhood socioeconomic conditions; however, that study was in adults, rather than children (Webb et al. 2008).

In common with other developed countries, Belarus has high levels of adult literacy, a clean regulated water supply, good sanitation levels, good healthcare coverage, long postnatal 
follow-up and low child mortality (Kramer et al. 2001; Lawrence 2001; World Health Organisation 2009). In contrast with most Western countries, Belarus has a relatively low Gross Domestic Product, high rates of adult mortality and long ( 3 years) obligatory maternity leave (Lawrence 2001; World Health Organisation 2009; Grigoriev et al. 2010). Our study, in this novel setting, may provide some insights into the mechanisms linking social and economic factors with growth in childhood. Socioeconomic factors may influence the tempo of growth (the speed at which a child reaches a mature size) via the effects of poverty; lack of nutrition, lack of exercise, exposure to pollution and overcrowding, which may affect skeletal growth and, hence, childhood height (Terrell and Mascie-Taylor 1991; $\mathrm{Li}$ et al. 2004b). None of parental age, smoking, alcohol intake, change in marital status nor breastmilk or cow's milk consumption, younger siblings or infant and childhood illness (including exploring gastrointestinal and respiratory illnesses specifically) explained socioeconomic inequalities in childhood height. In contrast, adjustment for both midparental height and number of older siblings markedly attenuated the associations between socioeconomic position and childhood height measures.

\section{Parental height, number of older siblings and socioeconomic differentials in childhood height}

There are a number of mechanisms by which mid-parental height might attenuate the association between parental socioeconomic position and offspring height. Parental height represents a complex combination of genes and environment in the parent's own intrauterine period and childhood (Cavelaars et al. 2000). Parental height is also associated with current socioeconomic position (Table IV). Offspring will often remain in the same socioeconomic position as their parents due to inter-generational transfer of socioeconomic disadvantage/advantage (Voss et al. 1998). Social mobility is also associated with height, number of siblings and education (Blane et al. 1999) and may be another means by which there is inter-generational transmission and accumulation of social disadvantage/advantage (Blane et al. 1999). Assortative mating for height (Mascie-Taylor 1987; Silventoinen et al. 2003) and social position (Mascie-Taylor 1987) has been reported in some studies. This suggests for example that taller individuals may be more likely to partner those of similar stature and/or be more likely to partner those with a similar level of education or social position through assortative mating (Mascie-Taylor 1987; Silventoinen et al. 2003). Tallness has also been associated with better attained education and occupation, leading to upward social mobility (Judge and Cable 2004; Magnusson et al. 2006). Over the generations this could effectively accumulate the genes for tallness within higher socioeconomic positions. The expression of these genes within an optimal environment may allow children to grow tall and affluent households are more likely to provide a favourable environment for growth. Conversely, among more deprived adults, over generations poorer mothers may accumulate genes for shorter stature which may be associated with a smaller uterus size and this may limit the size of the offspring, a poorer environment in childhood may also limit stature in the offspring. In addition, social and economic discrimination against persons of short stature (Judge and Cable 2004), combined with assortative mating, may compound these factors. However, an alternative explanation to our findings may be that the children's socioeconomic position-height associations reflect a delayed transgenerational effect, since it may require a number of generations to reach a height plateau after the removal of growthinhibiting constraints.

Late birth order is known to be associated with reduced stature ( $\mathrm{Li}$ and Power 2004; Lawson and Mace 2008; Hatton and Martin 2010), as are the related measures of having several siblings (Li and Power 2004; Hatton and Martin 2010), large family size (Li et al. 2004b; Hatton and Martin 2010) and overcrowded households (Li et al. 2004b). We found that controlling for older siblings resulted in the most marked attenuation of child height 
disparities as compared to controlling for younger siblings or total number of siblings. In our study, families from less educated/manual backgrounds were likely to have more children before the birth of the study child, e.g. $12.8 \%$ of manual households had two or more children at baseline compared to $5.8 \%$ of non-manual households. Notably, even in developed societies such as the UK, deficits in child height have been observed in families with large numbers of siblings and these findings remain after adjustment for socioeconomic position (Lawson and Mace 2008). Having many older siblings resulted in a greater and lasting reduction in height than having younger siblings (Lawson and Mace 2008). Furthermore, on examination of the quantity-quality trade-off, that is where parental resources are considered to be finite and there is a trade-off between the number of children and the resources allocated per child, those children from larger families had a reduced parental care score (Lawson and Mace 2009) and reduced per capita household income (Blane et al. 1999). This suggests that those from less affluent backgrounds may be required to spread resources (both material and psychosocial) among more family members, which could affect the child's living conditions and susceptibility to stress, illness and infection. Overcrowding or having older siblings may also increase the frequency of childhood infection (Silventoinen 2003). Overcrowding and bed sharing may in addition cause sleep disturbance, leading to reduced growth hormones and hence reduced height (Terrell and Mascie-Taylor 1991; Li et al. 2004b), although some studies report no such association (Gulliford et al. 1990).

\section{Strengths}

The strengths of the study include: (a) a large contemporary cohort of children, with excellent follow-up; (b) socioeconomic measures (parental education and occupation) were measured at the birth of the child and so were recorded before child height outcomes; (c) since the main aims of the PROBIT randomized trial included measuring prolonged and exclusive breastfeeding, gastrointestinal and respiratory infections, standing and sitting height, these measures were accurately assessed as shown by audit comparisons (Kramer et al. 2001; 2007).

\section{Limitations}

There are four main limitations to this study. First, the parents' heights were not directly measured; most were reported by the mother and thus may be prone to measurement error. Previous studies indicate that height tends to be over-estimated when self-reported and that this measurement error is differential, being greater in those from lower educational level/ manual backgrounds (Bostrom and Diderichsen 1997; Niedhammer et al. 2000). If this differential measurement error is present here, then the parental socioeconomic positionheight associations may be greater than we have found and may mean that the attenuation of the socioeconomic position-child height association with adjustment for parental height may be greater than actually observed. Height is likely to be less accurate if reported by a partner. Reassuringly, correlations of parental heights reported in other studies are very similar to our study. In a British sample the correlation of reported husbands and wives heights was 0.28 (Mascie-Taylor 1987) and in a European sample of measured parental heights was $0.13-0.37$ (Tanner et al. 1970) compared to our study findings of 0.27 .

Secondly, we measured all hospitalizations during infancy (0-12 months). However, in childhood (>12 months) we only included three types of hospitalization; those for gastrointestinal, pneumonia and asthma-related problems. We expect that this information was collected in a similar manner for all socioeconomic groups so expect no differential misclassification. We did not record data for those children hospitalized for other reasons during childhood, particularly between 1 and 2 years, which may be an important period for both health and stature. We may have omitted some hospitalizations and therefore under- 
estimated the effect of childhood illness on childhood height. Thirdly, we examined two major components of diet in infancy, but did not have any data on childhood diet beyond 1 year of age. Under-nutrition in this period may be an important mechanism to examine and we may have under-estimated the effects of childhood diet on height. Finally, we were unable to record associated measures of childhood living conditions, such as overcrowding, housing conditions, stress and physically strenuous work, all of which have been reported to impact on growth. However, those conditions that we were able to record (total number of siblings, mother's marital status change, parental smoking and alcohol intake) do give some indication of family size and childhood environment.

\section{CONCLUSION}

In Belarus, a middle-income country with recent major economic changes, socioeconomic differentials in height were observed in both 6.5 year old children and in their parents. Controlling for the heights of their parents and the number of older siblings partly explained these associations in children, suggesting that genetic influences and family circumstances are important factors in the development of height inequalities. Leg length was not a more sensitive indicator of early environmental conditions than trunk length in this setting.

There is evidence that the adverse impact of childhood poverty on health persists into late adulthood and short stature may act as a marker of this (Gunnell 2001). Our results demonstrate that height inequalities exist among both children and their parents, suggesting inequalities may still need to be tackled in Belarus.

\section{Supplementary Material}

Refer to Web version on PubMed Central for supplementary material.

\section{Acknowledgments}

The additional contributing members of the PROBIT Study Group are named. National Research and Applied Medicine Mother and Child Centre (Minsk, Belarus): Natalia Bazulko, Olga Gritsenko, Lidia Ovchinikova and Julia Rizkovskaya. Polyclinic paediatricians: Drs Natalia Andreeva (Rogachev), Tatiana Avdeichuk (Brest), Elena Avsiuk (Vitebsk), Irina Baikevich (Slonim), Zinaida Bisucova (Zlobin), Irina Bujko (Oshmiany), Tamara Galushkina (Volkovysk), Marina Gotovchi (Brest), Danuta Iodkovskaya (Berestovitsa), Galina Ivanova (Mogilev), Larisa Kebikova (Minsk), Galina Kluchnikova (Ostrovets), Maria Kotliarovich (Soligorsk), Galina Kovalevskaya (Lepel), Natalia Krokas (Mosty), Nadezda Kushkova (Rechitsa), Afanasia Lazarenko (Klimovichi), Ludmila Lazuta (Minsk), Zinaida Liamkina (Borisov), Raisa Lisiura (Stolin), Tamara Nabedo (Novolukoml), Svetlana Pleskach (Baranovichi), Oksana Potapenko (Soligorsk), Svetlana Pridhodoskaya (Bereuza), Valentina Rahotskaya (Oshmiany), Irina Rogach (Mstislavl), Ludmila Rutkovskaya (Kobrin), Natalia Senchuk (Rechitsa), Elena Seraia (Baranovichi), Ludmila Sheveleva (Kobrin), Vera Shota (Svisloch), Anna Silvanovich (Shuchin), Lilia Smolskaya (Glubokoe), Valentina Solovey (Volkovysk), Zoya Solovyova (Dokshitsy), Natalia Tsarik (Svetlogorsk), Nadezda Turkovskaya (Zlobin) and Oxana Zarodova (Minsk Region).

The hypotheses and statistical analysis plan were developed by RP, RMM and DAL. MSK and RMM contributed to obtaining funding for PROBIT fieldwork. RP performed the statistical analysis. RP wrote the first draft and cocoordinated completion of the paper. All authors critically commented on, edited earlier drafts and approved the final version of the paper. RP had full access to all the data in the study and takes responsibility for the integrity of the data and the accuracy of the data analysis.

None of the funding bodies influenced the data collection, analysis or its interpretation for this paper. The views expressed are those of the authors and not necessarily any funding body.

Declaration of Interest: Supported by a grant from the Canadian Institutes of Health Research (to MK) and from the European Union's project on Early Nutrition Programming: Long-term Efficacy and Safety Trials (grant code: FOOD-DT-2005-007036 to RMM and GDS). DAL \& GDS work in a UK Medical Research Centre (grant code: G0600705). DALs contribution to this work is supported by a UK Economic and Social Research Council large grant (grant code: RES-060-23-0011). 


\section{REFERENCES}

Batty GD, Leon DA. Socio-economic position and coronary heart disease risk factors in children and young people. Evidence from UK epidemiological studies. Eur J Public Health. 2002; 12:263-272. [PubMed: 12506501]

Blane D, Davey Smith G, Hart C. Some social and physical correlates of intergenerational social mobility: evidence from the west of scotland collaborative study. Sociology. 1999; 33:169-183.

Bobak M, Hertzman C, Marmot M. Own education, current conditions, parental material circumstances, and risk of myocardial infarction in a former communist country. J Epidemiol Community Health. 2000; 54:91-96. [PubMed: 10715740]

Bobak M, Kriz B, Leon DA, Danova J, Marmot M. Socioeconomic factors and height of preschool children in the Czech Republic. Am J Public Health. 1994; 84:1167-1170. [PubMed: 8017548]

Bostrom G, Diderichsen F. Socioeconomic differentials in misclassification of height, weight and body mass index based on questionnaire data. Int J Epidemiol. 1997; 26:860-866. [PubMed: 9279620]

Cavelaars AE, Kunst AE, Geurts JJ, Crialesi R, Grotvedt L, Helmert U, Lahelma E, Lundberg O, Mielck A, Rasmussen NK, Regidor E, Spuhler T, Mackenbach JP. Persistent variations in average height between countries and between socio-economic groups: an overview of 10 European countries. Ann Hum Biol. 2000; 27:407-421. [PubMed: 10942348]

Cohen S, Janicki-Deverts D, Chen E, Matthews KA. Childhood socioeconomic status and adult health. Ann N Y Acad Sci. 2010; 1186:37-55. [PubMed: 20201867]

Day NL, Leech SL, Richardson GA, Cornelius MD, Robles N, Larkby C. Prenatal alcohol exposure predicts continued deficits in offspring size at 14 years of age. Alcohol Clin Exp Res. 2002; 26:1584-1591. [PubMed: 12394293]

Department of Health. [accessed 18 January 2011] NHS. 2007. Available online at: http:// www.nhs.uk/livewell/alcohol/pages/effectsofalcohol.aspx

Freitas D, Maia J, Beunen G, Claessens A, Thomis M, Marques AN, Crespo M, Lefevre J. Socioeconomic status, growth, physical activity and fitness: The Madeira Growth Study. Ann Hum Biol. 2007; 34:107-122. [PubMed: 17536760]

Grigoriev P, Shkolnikov V, Andreev E, Jasilionis D, Jdanov D, Meslé F, Vallin J. Mortality in Belarus, Lithuania, and Russia: divergence in recent trends and possible explanations. Eur J Popul. 2010; 26:245-274.

Gulliford MC, Price CE, Rona RJ, Chinn S. Sleep habits and height at ages 5 to 11. Arch Dis Child. 1990; 65:119-122. [PubMed: 2301973]

Gunnell D. Commentary: early insights into height, leg length, proportionate growth and health. Int J Epidemiol. 2001; 30:221-222. [PubMed: 11369718]

Gunnell D, Okasha M, Davey Smith G, Oliver SE, Sandhu J, Holly JMP. Height, leg length, and cancer risk: a systematic review. Epidemiol Rev. 2001; 2:313-342. [PubMed: 12192740]

Gunnell DJ, Davey Smith G, Frankel SJ, Kemp M, Peters TJ. Socio-economic and dietary influences on leg length and trunk length in childhood: a reanalysis of the Carnegie (Boyd Orr) survey of diet and health in prewar Britain (1937-39). Paediatr Perinat Ep. 1998; 12, Suppl 1:96-113.

Hakeem R. Socio-economic differences in height and body mass index of children and adults living in urban areas of Karachi, Pakistan. Eur J Clin Nutr. 2001; 55:400-406. [PubMed: 11378815]

Hatton TJ, Martin RM. The effects on stature of poverty, family size, and birth order: British children in the 1930s. OEP. 2010; 62:157-184.

Hoppe C, Molgaard C, Michaelsen KF. Cow's milk and linear growth in industrialized and developing countries. Annu Rev Nutr. 2006; 26:131-173. [PubMed: 16848703]

Howe LD, Tilling K, Galobardes B, Davey Smith G, Gunnell D, Lawlor DA. Socioeconomic differences in childhood growth trajectories: at what age do height inequalities emerge? J Epidemiol Community Health. 2010 Available online at: http://jech.bmj.com/content/early/ 2010/08/18/jech.2010.113068.abstract.

International Labour Office Department of Statistics. [accessed 3 December 2010] ILO Database. 2011. Available online at: http://laborsta.ilo.org/

Judge TA, Cable DM. The effect of physical height on workplace success and income: preliminary test of a theoretical model. J Appl Psychol. 2004; 89:428-441. [PubMed: 15161403] 
Kramer MS, Chalmers B, Hodnett ED, Sevkovskaya Z, Dzikovich I, Shapiro S, Collet JP, Vanilovich I, Mezen I, Ducruet T, Shishko G, Zubovich V, Mknuik D, Gluchanina E, Dombrovsky V, Ustinovitch A, Ko T, Bogdanovich N, Ovchinikova L, Helsing E. Promotion of breastfeeding intervention trial (PROBIT): a cluster-randomized trial in the Republic of Belarus. Design, followup, and data validation. Adv Exp Med Biol. 2000; 478:327-345. [PubMed: 11065083]

Kramer MS, Chalmers B, Hodnett ED, Sevkovskaya Z, Dzikovich I, Shapiro S, Collet JP, Vanilovich I, Mezen I, Ducruet T, Shishko G, Zubovich V, Mknuik D, Gluchanina E, Dombrovskiy V, Ustinovitch A, Kot T, Bogdanovich N, Ovchinikova L, Helsing E, PROBIT Study Group (Promotion of Breastfeeding Intervention Trial). Promotion of Breastfeeding Intervention Trial (PROBIT): a randomized trial in the Republic of Belarus. JAMA. 2001; 285:413-420. [PubMed: 11242425]

Kramer MS, Guo T, Platt RW, Shapiro S, Collet JP, Chalmers B, Hodnett E, Sevkovskaya Z, Dzikovich I, Vanilovich I, PROBIT Study Group. Breastfeeding and infant growth: biology or bias? Pediatrics. 2002; 110:343-347. [PubMed: 12165588]

Kramer MS, Matush L, Vanilovich I, Platt RW, Bogdanovich N, Sevkovskaya Z, Dzikovich I, Shishko G, Collet JP, Martin RM, Davey Smith G, Gillman MW, Chalmers B, Hodnett E, Shapiro S, PROBIT Study Group. Effects of prolonged and exclusive breastfeeding on child height, weight, adiposity, and blood pressure at age $6.5 \mathrm{y}$ : evidence from a large randomized trial. Am J Clin Nutr. 2007; 86:1717-1721. [PubMed: 18065591]

Lawrence RA. Breastfeeding in Belarus. JAMA. 2001; 28:463-464. [PubMed: 11242433]

Lawson DW, Mace R. Sibling configuration and childhood growth in contemporary British families. Int J Epidemiol. 2008; 37:1408-1421. [PubMed: 18577530]

Lawson DW, Mace R. Trade-offs in modern parenting: a longitudinal study of sibling competition for parental care. Evol Hum Behav. 2009; 30:170-183.

Leary S, Davey Smith G, Ness A. Smoking during pregnancy and components of stature in offspring. Am J Hum Biol. 2006; 18:502-512. [PubMed: 16788904]

Li L, Dangour AD, Power C. Early life influences on adult leg and trunk length in the 1958 British birth cohort. Am J Hum Biol. 2007; 19:836-843. [PubMed: 17696141]

Li L, Manor O, Power C. Are inequalities in height narrowing? Comparing effects of social class on height in two generations. Arch Dis Child. 2004a; 89:1018-1023. [PubMed: 15499054]

Li L, Manor O, Power C. Early environment and child-to-adult growth trajectories in the 1958 British birth cohort. Am J Clin Nutr. 2004b; 80:185-192. [PubMed: 15213047]

Li L, Power C. Influences on childhood height: comparing two generations in the 1958 British birth cohort. Int J Epidemiol. 2004; 33:1320-1328. [PubMed: 15358746]

Lynch JW, Kaplan GA, Salonen JT. Why do poor people behave poorly? Variation in adult health behaviours and psychosocial characteristics by stages of the socioeconomic lifecourse. Soc Sci Med. 1997; 44:809-819. [PubMed: 9080564]

Mackenbach JP. Narrowing inequalities in children's height. Lancet. 1991; 338:764. [PubMed: 1679903]

Magnusson PKE, Rasmussen F, Gyllensten UB. Height at age 18 years is a strong predictor of attained education later in life: cohort study of over 950000 Swedish men. Int J Epidemiol. 2006; 35:658663. [PubMed: 16446353]

Martin RM, Kramer MS, Dahhou M, Platt RW, Patel R, Bogdanovich N, Matush L, Davey Smith G, Promotion of Breastfeeding Intervention Trial (PROBIT) Study Group. Do gastrointestinal tract infections in infancy increase blood pressure in childhood? A cohort study. J Epidemiol Community Health. 2010; 64:1068-1073. [PubMed: 19897470]

Martin RM, Smith GD, Mangtani P, Frankel S, Gunnell D. Association between breast feeding and growth: the Boyd-Orr cohort study. Arch Dis Child Fetal \& Neonatal Edition. 2002; 87:F193F201.

Mascie-Taylor CGN. Assortative mating in a contemporary British population. Ann Hum Biol. 1987; 14:59-68. [PubMed: 3592613]

Meyer HE, Selmer R. Income, educational level and body height. Ann Hum Biol. 1999; 26:219-227. [PubMed: 10355493] 
Niedhammer I, Bugel I, Bonenfant S, Goldberg M, Leclerc A. Validity of self-reported weight and height in the French GAZEL cohort. Int J Obesity Relat Metab Disord: IASO. 2000; 24:11111118.

Rona RJ, Chinn S, Florey CD. Exposure to cigarette smoking and children's growth. Int J Epidemiol. 1985; 14:402-409. [PubMed: 4055207]

Sichieri R, Taddei JA, Everhart JE. Influence of parental height and sociodemographic factors on adolescent height in Brazil. J Adolesc Health. 2000; 26:414-419. [PubMed: 10822183]

Silventoinen K. Determinants of variation in adult body height. J Biosoc Sci. 2003; 35:263-285. [PubMed: 12664962]

Silventoinen K, Kaprio J, Lahelma E, Viken RJ, Rose RJ. Assortative mating by body height and BMI: Finnish twins and their spouses. Am J Hum Biol. 2003; 15:620-627. [PubMed: 12953173]

Silventoinen K, Lahelma E, Lundberg O, Rahkonen O. Body height, birth cohort and social background in Finland and Sweden. Eur J Public Health. 2001; 11:124-129. [PubMed: 11420796]

Tanner JM, Goldstein H, Whitehouse RH. Standards for children's height at ages 2-9 years allowing for height of parents. Arch Dis Child. 1970; 45:755-762. [PubMed: 5491878]

Terrell TR, Mascie-Taylor CG. Biosocial correlates of stature in a 16-year-old British cohort. J Biosoc Sci. 1991; 23:401-408. [PubMed: 1939288]

Vingraite J, Bartkeviciute R, Michaelsen KF. A cohort study of term infants from Vilnius, Lithuania: feeding patterns. Acta Paediatr. 2004; 93:1349-1355. [PubMed: 15499957]

Voss LD, Mulligan J, Betts PR. Short stature at school entry-an index of social deprivation? (The Wessex Growth Study). Child Care Hlth Dev. 1998; 24:145-156.

Wannamethee SG, Shaper AG, Whincup PH, Walker M. Adult height, stroke, and coronary heart disease. Am J Epidemiol. 1998; 1:1069-1076. [PubMed: 9850129]

Webb E, Kuh D, Peasey A, Pajak A, Malyutina S, Kubinova R, Topor-Madry R, Denisova D, Capkova N, Marmot M, Bobak M. Childhood socioeconomic circumstances and adult height and leg length in central and eastern Europe. J Epidemiol Community Health. 2008; 62:351-357. [PubMed: 18339829]

Whitley E, Gunnell D, Davey Smith G, Holly JMP, Martin RM. Childhood circumstances and anthropometry: The Boyd Orr cohort. Ann Hum Biol. 2008; 35:518-534. [PubMed: 18821329]

WHO/UNICEF. Protecting, promoting and supporting breastfeeding: the special role of maternity services. World Health Organization; Geneva, Switzerland: 1989.

World Bank. [accessed 30 September 2010] 2010. Available online at: http://data.worldbank.org/

World Health Organisation. [accessed 29 January 2009] World Health Report. 2009. Available online at: http://www.who.int/whr/2004/annex/topic/en/annex_member_en.pdfhttp://www.who.int/kms/ resources/belarus.pdfhttp://www.who.int/whosis/mort/profiles/mort_euro_blr_belarus.pdf 


\section{Table I}

Association of socioeconomic indicators with child standing height measured at age 6.5 years in Belarus (2002-2005), $n=11074$

\begin{tabular}{|c|c|c|c|c|c|c|c|c|c|}
\hline & \multirow[b]{2}{*}{$n$} & \multirow[b]{2}{*}{$\%$} & \multicolumn{6}{|c|}{ Difference in child standing height $(95 \%$ confidence interval) $(\mathrm{cm})$} & \multirow[b]{2}{*}{$p$ sex int. } \\
\hline & & & Model 1 & $r^{2}$ & Model 2 & Model 3 & Model 4 & Model 5 & \\
\hline \multicolumn{10}{|l|}{ Mother's education } \\
\hline Initial/incomplete/common secondary & 3673 & 33 & 0 & & 0 & 0 & 0 & 0 & \\
\hline \multirow[t]{2}{*}{ Advanced secondary/partial university } & 5794 & 52 & 0.97 & & 1.02 & 0.77 & 0.76 & 0.44 & \\
\hline & & & $(0.73,1.21)$ & & $(0.81,1.24)$ & $(0.53,1.00)$ & $(0.53,1.00)$ & $(0.26,0.62)$ & \\
\hline \multirow[t]{2}{*}{ Completed university } & 1607 & 15 & 1.86 & & 1.88 & 1.34 & 1.34 & 0.71 & \\
\hline & & & $(1.46,2.25)$ & & $(1.49,2.28)$ & $(0.91,1.78)$ & $(0.90,1.77)$ & $(0.36,1.05)$ & \\
\hline$p$-value for trend & & & $<0.01$ & 0.018 & $<0.01$ & $<0.01$ & $<0.01$ & $<0.01$ & 0.85 \\
\hline \multicolumn{10}{|l|}{ Father's education } \\
\hline Initial/incomplete/common secondary & 4288 & 39 & 0 & & 0 & 0 & 0 & 0 & \\
\hline \multirow[t]{2}{*}{ Advanced secondary/partial university } & 5278 & 48 & 0.45 & & 0.52 & 0.35 & 0.35 & 0.14 & \\
\hline & & & $(0.09,0.81)$ & & $(0.18,0.85)$ & $(0.04,0.65)$ & $(0.04,0.65)$ & $(-0.14,0.42)$ & \\
\hline \multirow[t]{2}{*}{ Completed university } & 1508 & 14 & 1.20 & & 1.23 & 0.79 & 0.79 & 0.21 & \\
\hline & & & $(0.87,1.53)$ & & $(0.91,1.56)$ & $(0.48,1.10)$ & $(0.48,1.10)$ & $(-0.03,0.45)$ & \\
\hline$p$-value for trend & & & $<0.01$ & 0.009 & $<0.01$ & $<0.01$ & $<0.01$ & 0.12 & 0.86 \\
\hline \multicolumn{10}{|l|}{ Highest household occupation } \\
\hline Manual worker & 4715 & 43 & 0 & & 0 & 0 & 0 & 0 & \\
\hline \multirow[t]{2}{*}{ Non-manual worker } & 6359 & 57 & 1.02 & & 1.05 & 0.68 & 0.68 & 0.25 & \\
\hline & & & $(0.74,1.29)$ & & $(0.81,1.29)$ & $(0.44,0.92)$ & $(0.43,0.92)$ & $(0.01,0.50)$ & \\
\hline$p$-value for trend & & & $<0.01$ & 0.013 & $<0.01$ & $<0.01$ & $<0.01$ & 0.04 & 0.44 \\
\hline
\end{tabular}

Model 1: adjusted for urban or rural residence and East or West of Belarus.

Model 2: as Model 1 and additionally adjusted for study trial arm for breastfeeding promotion.

Model 3: as Model 2 and additionally adjusted for: parent's age, smoking and alcohol intake, number of older and younger siblings.

Model 4: as Model 3 and additionally adjusted for: hospitalizations in infancy or childhood for any reason.

Model 5: as Model 4 and additionally adjusted for: mid-parental height.

Robust standard errors were used to compute confidence intervals and $p$-values to account for clustering by polyclinic.

$p$ sex int. $=p$-value for sex interaction 


\section{Table II}

Association of socioeconomic indicators with child leg length measured at age 6.5 years in Belarus (20022005), $n=11074$

\begin{tabular}{|c|c|c|c|c|c|c|c|}
\hline & \multicolumn{6}{|c|}{ Difference in child leg length $(95 \%$ confidence interval) $(\mathrm{cm})$} & \multirow[b]{2}{*}{$\begin{array}{l}p \text { for sex } \\
\text { interaction }\end{array}$} \\
\hline & Model 1 & $r^{2}$ & Model 2 & Model 3 & Model 4 & Model 5 & \\
\hline \multicolumn{8}{|l|}{ Mother's education } \\
\hline Initial/incomplete/common secondary & 0 & & 0 & 0 & 0 & 0 & \\
\hline \multirow[t]{2}{*}{ Advanced secondary/partial university } & 0.43 & & 0.45 & 0.32 & 0.32 & 0.15 & \\
\hline & $(0.29,0.57)$ & & $(0.31,0.60)$ & $(0.18,0.47)$ & $(0.18,0.47)$ & $(0.03,0.27)$ & \\
\hline \multirow[t]{2}{*}{ Completed university } & 0.91 & & 0.92 & 0.63 & 0.62 & 0.29 & \\
\hline & $(0.67,1.14)$ & & $(0.68,1.15)$ & $(0.38,0.87)$ & $(0.38,0.87)$ & $(0.07,0.51)$ & \\
\hline$p$-value for trend & $<0.01$ & 0.010 & $<0.01$ & $<0.01$ & $<0.01$ & $<0.01$ & 0.77 \\
\hline \multicolumn{8}{|l|}{ Father's education } \\
\hline Initial/incomplete/common secondary & 0 & & 0 & 0 & 0 & 0 & \\
\hline \multirow[t]{2}{*}{ Advanced secondary/partial university } & 0.15 & & 0.18 & 0.09 & 0.09 & -0.02 & \\
\hline & $(-0.06,0.36)$ & & $(-0.03,0.38)$ & $(-0.09,0.28)$ & $(-0.09,0.27)$ & $(-0.19,0.15)$ & \\
\hline \multirow[t]{2}{*}{ Completed university } & 0.57 & & 0.58 & 0.34 & 0.34 & 0.03 & \\
\hline & $(0.36,0.77)$ & & $(0.37,0.79)$ & $(0.15,0.53)$ & $(0.15,0.53)$ & $(-0.14,0.20)$ & \\
\hline$p$-value for trend & $<0.01$ & 0.005 & $<0.01$ & 0.01 & 0.01 & 0.90 & 0.43 \\
\hline \multicolumn{8}{|l|}{ Highest household occupation } \\
\hline Manual worker & 0 & & 0 & 0 & 0 & 0 & \\
\hline \multirow[t]{2}{*}{ Non-manual worker } & 0.49 & & 0.51 & 0.32 & 0.32 & 0.09 & \\
\hline & $(0.35,0.64)$ & & $(0.36,0.65)$ & $(0.17,0.47)$ & $(0.17,0.47)$ & $(-0.06,0.24)$ & \\
\hline$p$-value for trend & $<0.01$ & 0.008 & $<0.01$ & $<0.01$ & $<0.01$ & 0.22 & 0.81 \\
\hline
\end{tabular}

Model 1: adjusted for urban or rural residence and East or West of Belarus.

Model 2: as Model 1 and additionally adjusted for study trial arm for breastfeeding promotion.

Model 3: as Model 2 and additionally adjusted for: parent's age, smoking and alcohol intake, number of older and younger siblings.

Model 4: as Model 3 and additionally adjusted for: hospitalizations in infancy or childhood for any reason.

Model 5: as Model 4 and additionally adjusted for: mid-parental height.

Robust standard errors were used to compute confidence intervals and $p$-values to account for clustering by polyclinic. 


\section{Table III}

Association of socioeconomic indicators with child trunk length measured at age 6.5 years in Belarus (20022005), $n=11074$

\begin{tabular}{|c|c|c|c|c|c|c|c|}
\hline & \multicolumn{6}{|c|}{ Difference in child trunk length $(95 \%$ confidence interval) $(\mathrm{cm})$} & \multirow[b]{2}{*}{$\begin{array}{c}p \text { for sex } \\
\text { interaction }\end{array}$} \\
\hline & Model 1 & $r^{2}$ & Model 2 & Model 3 & Model 4 & Model 5 & \\
\hline \multicolumn{8}{|l|}{ Mother's education } \\
\hline Initial/incomplete/common secondary & 0 & & 0 & 0 & 0 & 0 & \\
\hline \multirow[t]{2}{*}{ Advanced secondary/partial university } & 0.54 & & 0.57 & 0.44 & 0.44 & 0.29 & \\
\hline & $(0.37,0.71)$ & & $(0.42,0.72)$ & $(0.29,0.60)$ & $(0.28,0.60)$ & $(0.15,0.43)$ & \\
\hline \multirow[t]{2}{*}{ Completed university } & 0.95 & & 0.97 & 0.72 & 0.71 & 0.42 & \\
\hline & $(0.71,1.19)$ & & $(0.74,1.19)$ & $(0.45,0.98)$ & $(0.45,0.98)$ & $(0.20,0.64)$ & \\
\hline$p$-value for trend & $<0.01$ & 0.018 & $<0.01$ & $<0.01$ & $<0.01$ & $<0.01$ & 0.57 \\
\hline \multicolumn{8}{|l|}{ Father's education } \\
\hline Initial/incomplete/common secondary & 0 & & 0 & 0 & 0 & 0 & \\
\hline \multirow[t]{2}{*}{ Advanced secondary/partial university } & 0.30 & & 0.34 & 0.26 & 0.25 & 0.16 & \\
\hline & $(0.08,0.53)$ & & $(0.14,0.54)$ & $(0.07,0.44)$ & $(0.07,0.44)$ & $(-0.02,0.34)$ & \\
\hline \multirow[t]{2}{*}{ Completed university } & 0.63 & & 0.65 & 0.45 & 0.45 & 0.18 & \\
\hline & $(0.41,0.86)$ & & $(0.44,0.87)$ & $(0.23,0.67)$ & $(0.23,0.67)$ & $(-0.01,0.38)$ & \\
\hline$p$-value for trend & $<0.01$ & 0.011 & $<0.01$ & $<0.01$ & $<0.01$ & 0.05 & 0.55 \\
\hline \multicolumn{8}{|l|}{ Highest household occupation } \\
\hline Manual worker & 0 & & 0 & 0 & 0 & 0 & \\
\hline \multirow[t]{2}{*}{ Non-manual worker } & 0.53 & & 0.54 & 0.36 & 0.36 & 0.16 & \\
\hline & $(0.35,0.70)$ & & $(0.39,0.70)$ & $(0.21,0.51)$ & $(0.21,0.51)$ & $(0.01,0.31)$ & \\
\hline$p$-value for trend & $<0.01$ & 0.014 & $<0.01$ & $<0.01$ & $<0.01$ & 0.04 & 0.32 \\
\hline
\end{tabular}

Model 1: adjusted for urban or rural residence and East or West of Belarus.

Model 2: as Model 1 and additionally adjusted for study trial arm for breastfeeding promotion.

Model 3: as Model 2 and additionally adjusted for: parent's age, smoking and alcohol intake, number of older and younger siblings.

Model 4: as Model 3 and additionally adjusted for: hospitalizations in infancy or childhood for any reason.

Model 5: as Model 4 and additionally adjusted for: mid-parental height.

Robust standard errors were used to compute confidence intervals and $p$-values to account for clustering by polyclinic. 


\section{Table IV}

Association of socioeconomic indicators with standing height among parents from Belarus (2002-2005)

\begin{tabular}{|c|c|c|c|c|c|c|}
\hline & \multicolumn{3}{|c|}{$\begin{array}{c}\text { Difference in mothers standing height } \\
\text { (95\% confidence interval) }(\mathbf{c m}), n=12352 \\
\end{array}$} & \multicolumn{3}{|c|}{$\begin{array}{c}\text { Difference in fathers standing height } \\
(95 \% \text { confidence interval })(\mathrm{cm}), n=11235 \\
\end{array}$} \\
\hline & Model 1 & Model 2 & Model 3 & Model 1 & Model 2 & Model 3 \\
\hline \multicolumn{7}{|l|}{ Mother's education } \\
\hline Initial/incomplete/common secondary & 0 & 0 & 0 & 0 & 0 & 0 \\
\hline \multirow[t]{2}{*}{ Advanced secondary/partial university } & 0.46 & 0.42 & 0.44 & 1.49 & 1.37 & 1.32 \\
\hline & $(0.20,0.72)$ & $(0.15,0.68)$ & $(0.17,0.71)$ & $(1.13,1.85)$ & $(1.04,1.70)$ & $(0.99,1.65)$ \\
\hline \multirow[t]{2}{*}{ Completed university } & 0.88 & 0.84 & 0.88 & 3.05 & 2.90 & 2.79 \\
\hline & $(0.51,1.25)$ & $(0.49,1.19)$ & $(0.53,1.23)$ & $(2.54,3.55)$ & $(2.45,3.36)$ & $(2.33,3.24)$ \\
\hline$p$-value for trend & $<0.01$ & $<0.01$ & $<0.01$ & $<0.01$ & $<0.01$ & $<0.01$ \\
\hline \multicolumn{7}{|l|}{ Father's education } \\
\hline Initial/incomplete/common secondary & 0 & 0 & 0 & 0 & 0 & 0 \\
\hline \multirow[t]{2}{*}{ Advanced secondary/partial university } & 0.36 & 0.32 & 0.33 & 1.01 & 0.87 & 0.83 \\
\hline & $(0.11,0.62)$ & $(0.07,0.57)$ & $(0.08,0.57)$ & $(0.70,1.31)$ & $(0.59,1.15)$ & $(0.56,1.10)$ \\
\hline \multirow[t]{2}{*}{ Completed university } & 0.93 & 0.89 & 0.91 & 2.53 & 2.40 & 2.25 \\
\hline & $(0.54,1.32)$ & $(0.52,1.26)$ & $(0.54,1.28)$ & $(2.10,2.96)$ & $(1.98,2.82)$ & $(1.85,2.64)$ \\
\hline$p$-value for trend & $<0.01$ & $<0.01$ & $<0.01$ & $<0.01$ & $<0.01$ & $<0.01$ \\
\hline \multicolumn{7}{|l|}{ Highest household occupation } \\
\hline Manual worker & 0 & 0 & 0 & 0 & 0 & 0 \\
\hline \multirow[t]{2}{*}{ Non-manual worker } & 0.67 & 0.65 & 0.67 & 1.84 & 1.79 & 1.71 \\
\hline & $(0.49,0.85)$ & $(0.48,0.81)$ & $(0.50,0.84)$ & $(1.58,2.11)$ & $(1.58,2.00)$ & $(1.50,1.93)$ \\
\hline$p$-value for trend & $<0.01$ & $<0.01$ & $<0.01$ & $<0.01$ & $<0.01$ & $<0.01$ \\
\hline
\end{tabular}

Model 1: Adjusted for own age and study trial arm.

Model 2: as Model 1 and additionally adjusted for: urban or rural residence and East or West of Belarus residence.

Model 3: as Model 2 and additionally adjusted for: own smoking status and alcohol intake.

Robust standard errors were used to compute confidence intervals and $p$-values to account for clustering by polyclinic. 